Year:3, Volume:3, Number:6/Y11:3, Cilt:3 Sayı:6, 2019

DOI Number: 10.29064/ijma.535467

\title{
CONSUMER REGRET ARISING FROM SUB-OPTIMAL CONDITIONS IN STOCK- OUT SITUATIONS AND ITS' INFLUENCE ON BRAND LOYALTY
}

\author{
Newton Owuor OYUKE ${ }^{1}$ \\ Ümit ALNIAÇIK ${ }^{2}$
}

\begin{abstract}
Purpose- This study proposes to examine regret arising from consumer decision-making contexts in cases of stock out situation. Consumer regret under sub-optimal and optimal conditions and its influence on subsequent behavioral intentions of brand switching is investigated. Further, the study examines the effect of regret on brand loyalty and switching behavior.

Methodology- Data was collected from a convenient sample of 172 university students by using an online questionnaire circulated through social media platforms. Information about stock-out situation and sub-optimal condition is manipulated by a short excerpt in the questionnaire. Consumer responses in such a situation is measured by Likert type scales.

Findings- Data analyses revealed that there is a significant amount of regret experienced by consumers in stock out situations and suboptimal conditions which might lead to brand switching.

Conclusins-An enormous intent to switch brand was demonstrated. This denotes that when confronted with a comparable condition of purchasing a substitute brand during a stock out for the preferred brand, an individual may switch from the present vendor.
\end{abstract}

Keywords: Sub-optimal Condition, Brand Loyalty, Consumer Effect, Stock-out Situation, Regret

JEL Codes: M16, M31, M39

\section{INTRODUCTION}

Previous marketing scholars have examined the experiences and consequences of anticipated and experienced regret, the moderating roles of several key variables, and the effects of regret and disappointment on post-choice evaluations (Inman et al. 1997, Simonson 1992, Tsiros \& Mittal 2000). Generally, results show that an action may lead to regret upon learning about a better forgone alternative due to counterfactual thinking. Researchers have also studied the concept of future regret and have shown that consumers might minimize the experience of future feelings of regret by developing more stringent conditions for decision-making (Cooke et al. 2001). In general, the research focus has been on regret as a consequence of an action perceived by the consumer as providing the

\footnotetext{
${ }^{1}$ Kocaeli University. Email; owuor@live.com

2 Kocaeli University. Email; umit.alniacik@kocaeli.edu.tr
} 
highest expected utility at the time of decision-making (Zeelenberg 1999). However, in real life, consumers often knowingly make decisions in less than ideal conditions such as stock-outs. For example, it is a common phenomenon that sometimes products or brands desired by the consumer are not available and the consumer has to decide to buy another product (Fitzsimons 2000) or postpone the purchase (Dhar 1997). At times, in case of stock outs, consumers have to make decisions in sub-optimal conditions, such as when the available alternative is somewhat inferior to the preferred brand. Although there has been some research on consumer regret behavior, not much had been said about regret arising from sub-optimal conditions in stock-out situations. Accordingly, this study examines regret that consumers experience from decision making in stock out conditions. In this case, regret arises from buying and not buying a preferred brand. Preferred brand is assumed to be the brand that the consumer is likely to be loyal to. The consumer is either forced to buy another brand based on information she/he is given or received at the time of purchase or postpone the purchase. Such a situation may also influence consumer decision making process for the future purchases. Understanding antecedents and consequences of regret in sub-optimal condition may help marketers to better grasp consumer decision making processes. The next section provides a literature review on consumer regret behavior. Following the literature review, research methods and data analyses are provided.

\section{LITERATURE REVIEW AND THEORETICAL FRAMEWORK}

\subsection{Consumer Regret Behavior}

Regret in most cases can be defined as a magnitude of decision making that is done under risk and may arise when an individual seems to have made a wrong decision even if the decision appeared to be the right one at the time it was made (Davvetas, 2017). Regret ascends when someone feels or comprehends that the outcome of the option that he/she had rejected would have been the best choice. Regret is highly probable be experienced when one person finds out that the result of the rejected opinion might have been better (Zeelenberg, 1999). Regret is classified under the group of cognitive emotions. In other words, regret involves thinking of one's action before experiencing regret (Landman, 1993; Zeelenberg, 1999). Regret is not only about the experienced outcome but also the forgone outcome that might have occurred if a different approach had been taken.

In order to understand the intensity or nature of regret, it is also important to understand the difference between action-oriented regret and inaction-oriented regret (Cho et.al 2016). According to Wu\&Wang (2017), the issue that brings about the difference between action and inaction has been ignored in this context. They define action as something or an act that you had performed but you wish you hadn't performed it; and inaction as something you had not performed but you wish you had performed it (Wu\&Wang, 2017). The present study defines action as the act of purchasing a different brand instead of the favorite one that is recommended in stock out conditions. Inaction is defined as the act of not purchasing the brand that is recommended in case of stock out conditions.

Researchers have studied the general phenomenon of regret in marketing literature. Regret is incorporated in the model of expectancy-disconfirmation paradigm (Oliver, 1980). This paradigm provides a full description of consumer satisfaction to the consumers. Satisfaction 
has often been viewed as a major determining factor of consumer brand loyalty (Cho, et.al, 2016). Causes of satisfaction and dissatisfaction are important concepts in post choice evaluations by consumer. Taylor (1997) was among the first marketing researchers who suggested that expectations about unchosen alternative are most likely to affect one's choice especially if his expectations were not met by the choice. In order to prove this, Taylor conducted a research that had two experiments to test a number of hypotheses by including the expectation-disconfirmation model. Although the researcher obtained mixed outcomes, there was some evidence showing unchosen alternatives may also affect the satisfaction of individuals.

Inman et al (1997) continued with the research of Taylor. He incorporated "disappointment" in the earlier model of satisfaction. In his research model he includes three elements; each element signifies a particular factor that constitutes to an individual assessment of a chosen product. Expected performance is the first component model which is affected by the measure of anticipated performance. The second component, feelings of disappointment, this second component shows the difference between the anticipated and the actual performance. The third and last component is regret that is brought by making a comparison of the forgone alternative and the chosen product. Through "anchoring and adjustment" framework, the authors examined consumers' post choice valuation. The anchor here was the anticipated workability of the chosen product or service for both preevaluations and post evaluations. As an example, in situation where there is post-evaluation the anticipated performance is the anchor against which comparisons are formed. Consequently, the consumer undergoes disappointments and regret, the adjustments are then made according to the anchor. Research by Inman et al. (1997) has made a significant contribution to the research and understanding the role of regret on individual behavior. This is by merging the two concepts of regret and satisfaction in a model and the examining the effects on post- choice evaluations.

\subsection{Regret and Consumer Brand loyalty}

Consumer brand loyalty can be referred to as the consumers' behavior that indicates his/her desire to prolong or better an ongoing relationship with a product (Palmatier et al., 2006). Consumers' willingness to make a purchase of the product or service again of the same brand, having preference for the company or making recommendations to others about the product or service, the desire to prolong or remain in relationship with a particular product or service brand demonstrates how a consumer is related to a particular product or brand (Giovanis et al, (2017). Marketers always value consumers who are loyal to their brand or product since their willingness to repeat purchasing the product or service continuously. Marketers also value brand loyal consumers since they are reliable sources of revenue and they have a significant potential to make a spread of information about the product or service by positive word of mouth to others (Giovanis et al, (2017). In his research of the moderating role of consumer-brand identification on consumer responses to purchase regret, Davvetas (2017) concluded that regret decreases consumer satisfaction level and increases brand-switching intentions. Studies indicate that regret is most directly related to brand switching behavior (Popp and Woratschek, 2017). In a similar vein, the present study seeks 
to examine whether regret in stock out conditions causes brand switching or brand disloyalty.

\subsection{Regret Arising from Repeat Purchases and Those Arising from Switching Decisions.}

Liao et.al (2017) focused on showing that even though decision making provides a considerable indication that consumers are highly probable to experience more regret when they choose to change their status quo and the outcome is negative than when they choose not to change their position resulting in the same outcome. Occasionally the main reason for switching makes it appear like sustaining the status quo is not the only option available. In this case consumers are most likely to experience high levels of regret that they would have when they did not make the switch.

From the consumer buying behavior perspective, status quo can be defined as the tendency to make a repeated purchase, in this case to select the same brand over subsequent purchase decisions (Dean et.al 2017). In consumer decisions making the result of maintaining the status quo can be defined as follows: if a repeated purchase brings about a negative outcome, individuals are most likely to experience less amount of regret that if the negative outcome is brought about by purchasing a different brand other than the preferred one. However, such results due to maintaining the status quo might have been overrated, in the sense that there might have been certain previous occasions where the consumer might have been able to justify his/her reason for brand switching (Dean et.al 2017). This justification is therefore most likely to weaken the strength of regret that must have been felt earlier when the outcome became negative. On contrary, if the decisions to switching are not supported by good reasons then one should experience more regret and keep loyal to the focal (favorite) brand.

Based on the literature review presented above, we propose the following hypotheses:

H1: Consumers experience significant regret in sub-optimal decisions due to stock out situation when their decision is not supported by good reasons.

H2: Regret caused by sub-optimal decision positively influence consumer brand loyalty

H3: Regret caused by sub-optimal decision negatively influence the intention to switch the favorite brand

The next section provides the research methods and data analyses.

\section{RESEARCH METHOD}

In order to test and access the hypotheses, we conducted a field study employing survey methodology. The figure shown below depicts the model of the study. According to the model, the decisions not to purchase or purchase an alternative brand in stock out situations may always lead to the result of regret and brand switching might also be experience. 


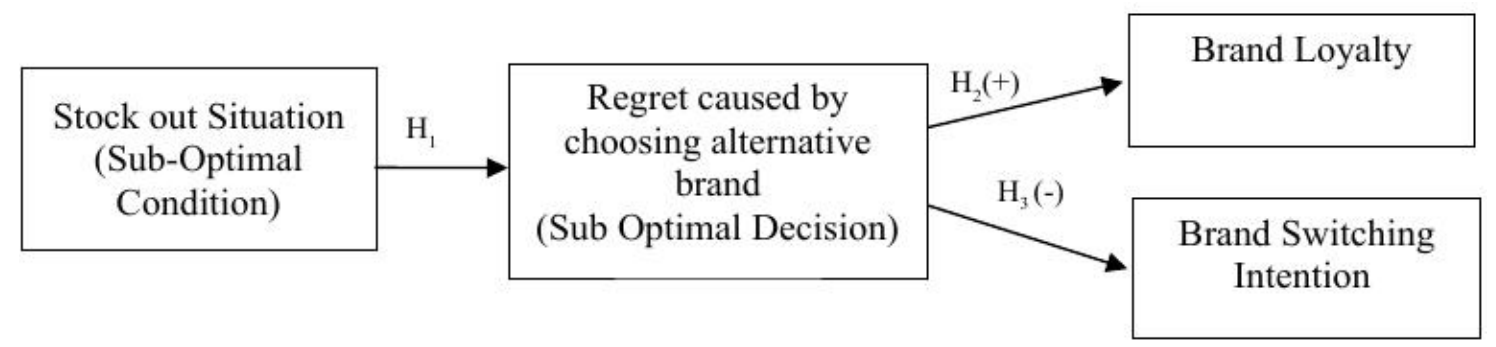

Figure 1: The Research Model

\subsection{Sample and Data Collection}

The survey incorporated a short scenario where a suboptimal decision-making situation is depicted. Respondents were asked to read the scenario and answer subsequent questions. The questionnaire was constructed online and distributed to emails and social media platforms (i.e. Facebook, WhatsApp and Messenger). The second set of questionnaires was physically administered to a conveniently selected sample of students at Kocaeli University, Turkey. A total of 172 respondents participated in the study. Following the demographic questions, a short story about a hypothetical customer's mobile phone shopping scenario is presented. Specifically, the scenario asked them to imagine that a subject named Ahmed was in a store to buy a mobile phone. However, upon his visit to a large consumer electronics store, in this case "Media Market" he found that there was a stock out for his preferred brand (favorite brand). The scenario further stated that Ahmet decided to go through the available brands that were in the store. Ahmed then came across an available brand that was similar to the preferred (stock out) brand and would most likely be of the same functional value as the stock out brand. For proper comprehension of the scenario, a brief introduction was provided following which the respondents were informed about what occurred when Ahmet visited the store to buy his preferred brand. Specifically, the respondents were told: Imagine that Ahmet is shopping for a smart phone. For the past couple of months, he has been looking at various brands of smart phones and ultimately had managed to narrow it down to one brand that he would prefer to buy. Ahmed has always previously bought the same brand of phone, from the same provider. The respondents were then informed that consumer Reports rated the available brand as either superior (in the inaction condition) or inferior (in the action condition) in order to induce regret and its consequences such as, intentions to switch and to complain by the consumers. After reading the scenario, the subjects were asked to respond to subsequent questions in the form. The respondents were to state what they would do or how they would respond if they were in Ahmet's position. In the end, the subjects were thanked.

\subsection{Study Variables and Measures}

Stock out Situation: The independent variable is manipulated by a short story. According to the story, the stock out situation occurs when the subject visits the store and does not find his preferred item of choice instead the subject finds an alternative to his preferred item. This is how the participants were informed of this situation: "Ahmet goes to a large consumer electronics store, like Media Market, to purchase his preferred brand 
(PREF BRAND) of smart phone. However, much to his disappointment he finds that it is out of stock and not available"

Sub Optimal Condition: Sub Optimal condition in this scenario means that the available brand or item of choice is inferior/superior to the preferred brand. This information is later manipulated in the scenario as follows: A couple of days after buying the available brand, the customer comes across consumer rating reports showing the available brand is inferior/superior to the favorite brand.

Regret: Respondents completed a three-inter-item regret scale that assessed their regret emanating from their decision of action regarding the available brand. The items were: "You would feel sorry for your decision to buy the available brand other than the preferred brand" (strongly disagree/strongly agree); "You would regret your decision regarding the available brand" (strongly disagree/strongly agree); "You would wish you had not made the decision regarding the available brand" (strongly disagree/strongly agree).

Switching Intention: Respondents' intention to switch their favorite brand (to the available brand) is measured by a single item: "You think you would switch to buying the available brand in the future" (strongly disagree/strongly agree);

Brand Loyalty: Respondents' intention to behave loyal to their favorite brand (the unavailable brand) is measured by a single item: "You think you would retain buying the unavailable (favorite) brand in the future" (strongly disagree/strongly agree).

All dependent variables were assessed using seven-point scales anchored by $1=$ strongly disagree and $7=$ strongly agree.

\section{FINDINGS}

One hundred and seventy-two respondents (44.8\% female and $55.2 \%$ male, with an average age group of 18-25 years) correctly responded to all of the questions. 72 respondents physically completed the questionnaire while 100 respondents filled the online questionnaire that was shared through social media platforms. Data is entered into SPSS spreadsheet to perform the analyses. A preliminary $t$ test was performed to check if there was any significant difference between the responses caused by data collection method. No significant difference is detected between the responses given to online and paper-pencil questionnaire.

Before testing research hypotheses, exploratory factor analysis and reliability analysis were performed to check the dimensionality and reliability of the regret scale. Principal components analysis revealed a single factor for the regret scale which explained $66,2 \%$ of the total variance. All of the scale items heavily loaded onto this single factor. Cronbach Alpha coefficient is found to be 0,74 . Consequently, we created a composite regret variable by averaging three items under regret scale. The mean score of this composite variable is 4,68 showing a significant difference from the mid-point $(3,5)$ of the 1-7 range scale $\left(\mathrm{t}_{171}=9,529, \mathrm{p}<0,001\right)$. The composite variable is used in correlation analyses in order to test the research hypotheses. Table 1 shows descriptive statistics and exploratory factor analysis results along with the reliability coefficient. 
Table 1. Regret Scales Items, Descriptive Statistic s and Exploratory Factor Analysis Results

\begin{tabular}{|c|c|c|c|c|c|}
\hline Item & Mean & $\begin{array}{l}\text { Standard } \\
\text { Deviation }\end{array}$ & $\begin{array}{l}\text { Factor } \\
\text { Loads }\end{array}$ & $\begin{array}{l}\text { Explained } \\
\text { Variance \% }\end{array}$ & $\begin{array}{l}\text { Cronbach } \\
\text { Alpha }\end{array}$ \\
\hline $\begin{array}{l}\text { You would feel sorry for your decision to } \\
\text { buy the available brand over the preferred } \\
\text { brand }\end{array}$ & 4.988 & 1.913 & 0.657 & \multirow{3}{*}{66,292} & \multirow{3}{*}{0,74} \\
\hline $\begin{array}{l}\text { You would regret your decision regarding } \\
\text { the available brand }\end{array}$ & 4.459 & 1.998 & 0.903 & & \\
\hline $\begin{array}{l}\text { You would wish you had not made the } \\
\text { decision regarding the available brand }\end{array}$ & 4.593 & 2.093 & 0.862 & & \\
\hline
\end{tabular}

In the next stage, we performed two different correlation analyses to examine the relations between regret, intentions to switch brand and brand loyalty. As seen in Table 2, correlations among study variables reveal that regret is significantly negatively correlated to intentions to switch favorite brand ( $\mathrm{r}=-0.161, \mathrm{p}=0.035)$. Further, regret (in case of suboptimal decision due to stock out condition) is found to be significantly positively correlated with brand loyalty $(\mathrm{r}=0.294, \mathrm{p}<0.001)$. Thus, our second hypothesis $(\mathrm{H} 2)$ proposing that regret caused by sub-optimal decision positively influence consumer brand loyalty, and our third hypothesis (H3) proposing that regret caused by sub-optimal decision negatively influence the intention to switch the favorite brand are supported.

Table 2. Means, Standard Deviations, and Interrelations of Study Variables

\begin{tabular}{|l|c|c|c|c|c|}
\hline Item & Mean & $\begin{array}{l}\text { Standard } \\
\text { Deviation }\end{array}$ & (1) Regret & (2) Switch & (3) Loyalty \\
\hline (1) Regret & 4,68 & 1,62 & & & \\
\hline (2) Brand Switch Intention & 3,38 & 2,19 & $-0,161^{*}$ & & \\
\hline (3) Brand Loyalty & 5,12 & 2,01 & $0,294^{* *}$ & $-0,58$ & \\
\hline
\end{tabular}

*Correlation is significant at the 0.05 level (2-tailed).

**Correlation is significant at the 0.01 level (2-tailed).

\section{CONCLUSION AND DISCUSSIONS}

The experience of regret has been a major topic of concern among the scholars in the fields of psychology and marketing. Researchers in marketing psychology have examined a variety of issues that are in relation to regret. For example, investigation has been conducted into defining and understanding the affective responses of regret (elation) arising from action versus inaction subsequent to negative (positive) outcomes (Landman 1988), the existence of a chronological design of regret (Gilovich and Medvec 1995), the role of counterfactual believes in the know-how of regret (e.g. Zeelenberg et al. 1998), the functionality of the sensation (Zeelenberg 1999), and the inaction effect in regret (e.g. Zeelenberg et al. 2002). In divergence, research in the domain of psychological marketing has been more concentrated, unambiguously scrutinizing in profundity the reaction from the buyer's perception of post choice assessment (e.g. Cooke et al. 2001, Inman et al. 1997, Inman and Zeelenberg 2002, Simonson 1992, Taylor 1997, Tsiros and Mittal 2000). Marketing scholars have assumed that integrating regret in the disconfirmation-expectation model of satisfaction offers the customers with a more well-off explanation of post-choice 
assessment (Inman et al. 1997, Taylor 1997). In addition, studies are also shepherded to study the interactive consequences of the reaction that individuals go through when individuals are made to contemplate regret before purchasing a merchandise (Simonson 1992), the consequence of undergoing regret after an undesirable aftermath (Tsiors and Mittal 2000), and how the significance of experienced remorse might have emotional impact on consumers' forthcoming choice actions (Cooke et al. 2002).

The perseverance of this study is to shed light on when regret originating from action in sub optimal situations might lead to brand switching or keeping loyal to the favorite brand. In optimal conditions it is anticipated that an individual makes a resolution established on uppermost anticipated utility to be imitative from such a resolution. For instance, one decides on trademark B over trademark A or trademark C because he/she have confidence in trademark B is likely to offer maximum anticipated utility. Nevertheless, consumers frequently experience circumstances which are sub-optimal, for instance when the preferred brand $\mathrm{B}$ is out of stock and a resolution is made concerning trademark $\mathrm{A}$, to some extent a substandard trademark. Does he/she continually experience (avoid) regret for the reason of acquiring (not purchasing) brand A? As will be deliberated later, action does not always result in regret and inaction does not always result in avoiding regret in suboptimal conditions. Subsequent evaluations after buying the alternative brand significantly affects customers' intention to switch or keep loyal to the favorite brand. In the current study, we conclude that consumers experience significant regret in sub-optimal decisions due to stock out situation when their decision is not supported by good reasons; and this kind of a regret (in case of action not supported by good post-purchase evaluations) positively influences consumer brand loyalty (to the favorite brand) and negatively influences their intention to switch the favorite brand.

As hypothesized, the outcomes indicate that individuals experience superior regret in sub optimal conditions. This is in line with the outcomes of the previous study dealing with regret (e.g. Gilovich and Medvec 1995, Landman 1993) where it has been recommended that action is more protuberant than inaction. This means that, it is tranquil for individuals to conceive not undertaking something (after they have done it) than it is to envision doing something (after not having done it). The tranquility is for individuals to produce counterfactual thoughts after an unscrupulous resolution, the inordinate is the strength of regret experienced. Henceforth consequent to a deleterious outcome, individuals are likely to experience significant regret when they made their decision to procure the available brand than when they made their personal decision not to procure the available brand. In addition, one also regrets the circumstance when he is trapped with substandard merchandise.

As hypothesized, individuals demonstrate an enormous intent to switch. This denotes that when confronted with a comparable condition of purchasing a substitute brand during a stock out for the preferred brand, an individual may switch from the present vendor in order to diminish the probabilities of acquiring substandard merchandise over again. In relation to aforementioned study, regret and switching intentions are certainly interconnected (e.g. Tsiros and Mittal 2000). Henceforth, in the action circumstance when one experiences enormous regret as a result of the commendation from a non-expert subsequent to a negative outcome, it is in the offing that switching intentions will follow the equivalent configuration as regret experienced. 


\subsection{Theoretical and Practical Contributions}

Prevailing investigations on regret in the dominion of marketing has predominantly concentrated on the emotion ascending from an inaction taken by an individual. Research in psychology, on the other hand, has showed that regret may very well ascend from action, i.e. where the individual fails not to act. Even though, a momentous expanse of research demonstrate that actions stimulate greater regret than inactions (nominated as the most replicated discovery in regret investigation in psychology by Zeelenberg et al. (2002)), there is a sturdy brook of research that hostages this reflection. For instance, Gilovich and Medvec (1995) uphold that regret follows a chronological configuration. To be precise, in due course bigger regret is experienced from inaction than from action, while in the diminutive run bigger regret is experienced from action than from inaction. Zeelenberg et al. (2002) also indicated that when pronouncements are made chronologically, in certain circumstances, regret arising from inaction is greater than that arising from action, depending on the valence of the preceding resolution conclusions. This study identifies a condition in the domain of marketing when regret originates from action, in the occurrence of stock out and sub optimal condition. As anticipated, it was established that, when there is a corroboration of the suboptimal condition, action leads to regret. It is imperative to note that preceding regret research has predominantly scrutinized the experience of regret originating from a resolution under optimal conditions. Nevertheless, individuals are also likely to make resolutions under sub-optimal conditions. Research on regret has stayed mute with reference to decision making under sub-optimal conditions and there may perhaps be a worth mentioning consequence of investigating such sub-optimal versus optimal conditions of consumer decision making. Preceding inquiries in the domain of regret has advanced several questions for the degree of difference in regret due to action versus inaction. One significant reason is emotional intensification (Gilovich and Medvec 1995) based on norm theory. Emotional intensification emphasizes that subsequent to a negative conclusion, an emotion experienced by an individual is likely to be amplified when the cause of the undesirable outcome is a situation being away from the normal.

In relation to practical contribution, the conclusions of this study imply that retail institutions should have enhanced redressal structures so that consumers are encouraged to protest their undesirable experience. Subsequently, deprived of consumer grievances the retailer may not be responsive of its inadequacies, but progressively will continue to lose its customer base. Secondly, it might be far-sighted for the vendor to let a consumer make his/her own decision in the event of a stock out for a preferred brand. Evidently, salespeople should be accessible to help the consumer make the decision if indispensable, but even professional salespeople should be cautious while enlightening or commending an available brand to the consumer. Lastly, the vendors should guarantee that even professional salespeople remain copiously conversant about the product market and the most recent advances in such market. As the outcomes point out, the acquisition of an available brand resulting to an undesirable aftermath results in individuals expressing superior intents keep loyal to their favorite brand.

\subsection{Limitations of the Study}

The above study has obvious limitations, as an example measuring of the intentions of brand switching instead of the actual behavior. In addition, the normality of behavior was 
not assessed, example we assumed the normality of buying available brand when the preferred brand was not available and that the available brands would be of low rate. It is therefore suggested that prior to the study normality of behavior should be assessed. The study also was limited to a conveniently selected student sample as the subjects; and a mobile phone as the product. This may have hampered the generalizability of the findings. It is therefore suggested that a replica of the study might be done using non-students as subjects and other types of products which might lead to a higher degree of validity. Further, this study could be improved by incorporating different post-action scenarios (i.e. manipulating the information about the available brand after buying it). Last but not the least, instead of using single item measures to capture brand switch intentions and loyalty, more comprehensive measures covering multidimensional structure of these variables could be used.

\section{REFERENCES}

Cho, S.B., Jang, Y.J. \& Kim, W.G. (2016). "The Moderating Role of Severity of Service Failure in the Relationship among Regret/Disappointment, Dissatisfaction, and Behavioral Intention," Journal of Quality Assurance in Hospitality \& Tourism, 18(1), 69-85.

Cooke, A.D.J., T. Meyvis and A. Schwartz (2001). "Avoiding Future Regret in PurchaseTiming Decisions" Journal of Consumer Research, 27(4), 447 - 459.

Cooke, R. Sniehotta,F. Schüz, B. (2007). "Predicting Binge-Drinking Behavior Using an Extended Tpb: Examining The Impact of Anticipated Regret and Descriptive Norms" Alcohol and Alcoholism, 42(2), 84-91

Davvetas, V. (2017). "Regretting your brand-self?" The moderating role of consumer-brand identification on consumer responses to purchase regret," Journal of Business Research, 80(November), 218-227.

Dean, M., Kıbris,Ö. and Masatlioglu Y., (2017). "Limited attention and status quo bias" Journal of Economic Theory, 169 (May), 93--127.

Dhar, R. (1997). "Consumer Preference for a No-Choice Option" Journal of Consumer Research, 24 (2), 215 - 231.

Fitzsimons, G.J. (2000). "Consumer Response to Stock outs" Journal of Consumer Research, 27(2), $249-266$.

Gilovich, T., and V.H. Medvec (1995). "The Experience of Regret: What, When and Why" Psychological Review, 102(2), 379 - 395.

Giovanis, A.N. and P. Athanasopoulou, (2017). Consumer-brand relationships and brand loyalty in technology-mediated services" Journal of Retailing and Consumer Services,40(1), 287-294. 
Inman, J.J., James S. Dyer and Jianmin Jia (1997). "A Generalized Utility Model of Disappointment and Regret Effects on Post-Choice Valuation" Marketing Science, 16(2), $97-111$.

Inman, JJ. Zeelenberg, M. (2002). "Regret in Repeat Purchase Versus Switching Decisions: The Attenuating Role of Decision Justifiability" Journal of Consumer Research, 29(1) (June), $116-128$.

Landman, J. (1988). "Regret and elation following action and inaction: Affective responses to positive versus negative outcomes" Personality and Social Psychology Bulletin, $13,524-536$.

Landman, J. (1993). Regret: The Persistence of The Possible, New York, Oxford University Press.

Liaoa, C. Hong-Nan Lin, Margaret Meiling and Luo Sophea Cheac, (2017). Factors influencing online shoppers repurchase intentions: The roles of satisfaction and regret. Journal of Information \& Management, 54(5), 651-668.

Oliver, R. L. (1980). A cognitive model of the antecedents of satisfaction decisions. Journal of Marketing Research, 17(4), 46-49.

Palmatier, R. W., Dant, R.P., Grewal, D., \& K. Evans (2006). "Factors influencing the effectiveness of relationship marketing: A Meta-Analysis" Journal of Marketing, 70(4), 136-53.

Popp, B. and H. Woratschek (2017).“Consumer-brand identification revisited: An integrative framework of brand identification, customer satisfaction, and price image and their role for brand loyalty and word of mouth" Journal of Brand Management 24 (3), 250-270.

Simonson, I. (1992), "The Influence of Anticipating Regret and Responsibility on Purchase Decisions" Journal of Consumer Research, 19 (1), 105 - 118.

Taylor, K. (1997). A Regret Theory Approach to Assessing Consumer Satisfaction, Marketing Letters, Vol.8, Iss.2, pp 229-238

Tsiros, M. and Mittal, V. (2000). "Regret: A Model of Its Antecedents and Consequences in Consumer Decision Making" Journal of Consumer Research, 26(4), 401 - 417.

Wu, R., Wang, C.L. (2017) "The asymmetric impact of other-blame regret versus selfblame regret on negative word of mouth: Empirical evidence from China", European Journal of Marketing, 51 (11/12), 1799-1816

Zeelenberg, M. (1999). "The Use of Crying Over Spilt Milk: A Note on The Rationality and Functionality of Regret," Philosophical Psychology, 12(3), 325 - 340.

Zeelenberg, M., E. VanDijk, K. Van-denBos and R. Pieters (2002). "The Inaction Effect in the Psychology of Regret," Journal of Personality and Social Psychology, 82(3), $314-327$. 